\title{
FERMÍN HERRÁN Y EL ATENEO LITERARIO LA CASA DE CERVANTES EN VALLADOLID (1872)
}

El contenido de este trabajo es una aproximación biográfica y cultural a un escritor vasco de segunda fila, cuyo interés se fundamenta en varios motivos. Los documentales, es decir, su afición y devoción a la figura de Miguel de Cervantes, se verán a continuación en un conjunto de referencias que he podido extraer después de larga búsqueda ${ }^{1}$.

Pero hay otros motivos que, como es natural a su profundidad humana, no son visibles en la documentación y es preciso señalarlos o por lo menos destacar su relevancia.

Después de recomponer esta tan secundaria como heroica biografía observando los tiempos revueltos en que llevó a cabo sus continuos proyectos culturales y publicaciones, lo que más sorprende es el hecho de que un intelectual vasco como él pusiera tanto empeño hace poco más de cien años en pretender levantar y esgrimir la figura de Miguel de Cervantes, emblema y personificación de la unidad cultural española, para conjurar al demonio de la discordia legitimista que enfrentaba entonces a carlistas y liberales, y todo ello en ese territorio fronterizo que es Castilla la Vieja, y más concretamente en la ciudad de Valladolid.

1 La realización del presente trabajo no hubiera sido posible sin la inestimable ayuda de doña Rosa María Callejo Gago, directora del Archivo Municipal de Valladolid; doña Beatriz Estefanía Pando, directora de la Biblioteca General "Reina Sofía» de Valladolid; doña Amparo Magdaleno, directora de la vallisoletana Casa de Cervantes; doña Ángeles Moreno López, directora del Archivo de la Universidad de Valladolid; doña Beatriz Fernández Suzor, de la Biblioteca General de Medinaceli (CSIC), y doña Pilar Martínez Olmo, directora de la Biblioteca del Instituto de Filología del CSIC. 
Para entender lo extraordinario de esta posición habría que recordar el contexto sociopolítico en que se produce. Como se verá enseguida, este proyecto de Fermín Herrán de recuperar la advocación cultural de Cervantes se produce entre 1872 y 1873. Unos meses en que los carlistas aprovechan el vacío institucional que se produce con la salida de España de Isabel II como consecuencia de la Gloriosa o Septembrina de 1868, para reiniciar una campaña bélica prolongada hasta 1876 con el fin de alcanzar el trono español que según ellos les pertenece legítimamente.

Fermín Herrán es un hijo espiritual del progresismo republicano de esa Revolución de 1868. Para él como para los krausistas, la cultura es el camino más seguro para la liberación y la realización del ser humano. La cultura estimula lo mejor del ser humano y facilita su desarrollo más pleno.

En Valladolid y en 1872 tiene Fermín Herrán el encuentro que ahora se verá con Miguel de Cervantes. Su respuesta, si recordamos como referencia el discurso de don Quijote sobre las armas y las letras (I, XXXVII), fue seguir el camino de las letras, el mismo que siguió Cervantes contra la inclinación belicista de su personaje. Sin la ironía de este nuestro escritor universal, que utiliza las letras, su escritura, para construir la idea en sus oyentes, los próximos (nobles y de vidas extraordinarias), y nosotros, de que las armas están por encima, Fermín Herrán querrá levantar la bandera de este gigante de las letras contra el estruendo de las armas. Su biografía es la historia de su fracaso, un fracaso que él mismo intuía en los últimos años de su vida.

En Bilbao, y a 30 de octubre de 1896, ponía fin Fermín Herrán a la biografía de Juan Eustaquio Delmas que acompaña al tomo primero de su libro Cosas de antaño. Capítulos históricos, y que él mismo le publicó como volumen quinto de su magna «Biblioteca Bascongada de Fermín Herrán» ${ }^{2}$.

En su recorrido biográfico planteaba Herrán la suerte que cabe a los escritores: aquellos que alcanzan reconocimiento general en vida y, además, pasan a la posteridad, y aquellos que, a pesar de su

labor incesante, aun siendo valiosa y meritoria, no suelen tener, al menos durante su vida, la recompensa de que son dignos, sacando sólo, de un constante trabajo, la fatiga y el amargor que le acompañan, y habiendo quienes ni siquiera logran después de muertos el recuerdo de que han existido ${ }^{3}$.

2 De ella me he ocupado en el Homenaje a Juan Maria Diez Taboada (en prensa).

3 FERMín HERRÁN, "Juan Ernesto [sic] Delmas. Biografía", en JUAN ERNESTO [sic] Delmas, Cosas de antaño. Capítulos históricos, tomo I. Bilbao, Imp. de la «Biblioteca Bascongada», 1896, p. 202 («Biblioteca Bascongada de Fermín Herrán», tomo $\left.5^{\circ}\right)$. 
Nada más exacto que este juicio para caracterizar al mismo Herrán, animador cultural, publicista, crítico literario y entusiasta cervantista, cuya aportación a nuestra historia literaria ha quedado silenciada de manera bastante injusta.

\section{Breve aproximación biográfica de Fermín Herrán}

Nacido en 1852 en Salinas de Añana (Álava) en el seno de una familia acomodada ${ }^{4}$, tuvo la suerte de vivir siendo muy joven la breve explosión cultural de Vitoria tras el triunfo de la Revolución de Septiembre.

La vida cultural vitoriana había comenzado a animarse con la inauguración en 1866 del Ateneo Científico, Literario y Artístico, promovido por tres profesores del Instituto Provincial, Eduardo Orodea, Antonio Pombo y Cristóbal Vidal ${ }^{5}$. Pero sería la apertura de las aulas de su Universidad en 1869 la que llevaría a convertir a la capital alavesa durante algunos años en «la Atenas del Norte» 6.

Al estímulo de las libertades conseguidas tras la Revolución del 68, de la que será buena prueba la nueva Universidad, responden los vitorianos con la «Asociación Liberal Vitoriana», en la que se integraron los jóvenes republicanos.

Entonces - decía Becerro de Bengoa en 1891- estaba en su apogeo el Círculo filarmónico, la sociedad de recreo más admirable que Vitoria ha conocido en esta última mitad del siglo, y en la que nuestra juventud lució sus méritos artísticos de actores y de autores, de poesía y de música ${ }^{7}$.

De 1869 data también la creación del «Centro Literario Vascongado», promovido por Becerro de Bengoa, Francisco Juan de Ayala y Sotero Manteli, con el objeto de publicar «las obras relativas al país» ${ }^{8}$.

4 Vid. JUAN VIDAL-ABARCA y LóPEZ, Los Herrán: Historia y genealogía de una familia vasca. Vitoria-Gasteiz, Dpto. de Cultura-Diputación Foral de Álava, 1993.

5 José Daniel Reboredo Olivenza, El Ateneo Científico, Literario y Artístico de Vitoria (1866-1900). Vitoria-Gasteiz, Diputación Foral de Álava, 1988.

6 Eduardo Velasco LÓPEZ CANO, Crónicas y biografías alavesas. Vitoria, Imp. Provincial, 1910, p. 140.

7 Ricardo Becerro De Bengoa, «Don Daniel Ramón de Arrese. Recuerdos de su vida», en DANIEL R. DE ARRESE, Escritos, volumen primero. Bilbao, Imp. y Enc. de Andrés P.-Cardenal, 1900, p. 16 («Biblioteca Bascongada de Fermín Herrán», tomo 53). Estos «Recuerdos» de Becerro aparecieron inicialmente en la revista Euskal Erria, XXV, 1891, pp. 257-265.

8 Ricardo BecERro DE BENGOA, El libro de Álava. Vitoria, Imp. de los Hijos de Manteli, 1877, p. 176. 
$\mathrm{Al}$ año siguiente el joven Manuel Iradier y Bulfy pone en marcha la «Joven Exploradora», que se transformaría en 1872, por iniciativa de Enrique Serrano Fatigati, catedrático del Instituto, en "Academia Alavesa de Ciencias de Observación» 9.

A pesar de que, como se lamentaba Becerro de Bengoa,

la maldita guerra civil, con sus miserias, apagó aquel foco de luz y de progreso y detuvo todo el movimiento de la ilustración bascongada [sic] ${ }^{10}$,

la participación de Fermín Herrán en el enriquecimiento cultural de Vitoria durante estos años fue muy significativa. Apenas cumplidos los 19 años pone en circulación en septiembre de 1871 el semanario político-fuerista, científico-literario, El Porvenir Alavés, que llegaría hasta $1877^{11}$. En 1872 edita el primer volumen de un ambicioso proyecto, la "Biblioteca Escogida de Fermín Herrán» ${ }^{12}$. A comienzos del año siguiente se embarca en una nueva aventura editorial, las "Obras de Don Fermín Herrán», que inauguraba con un folleto de 55 páginas sobre el drama de Eulogio Florentino Sanz, Don Francisco de Quevedo, y principio de una serie dedicada a la formación de unos «Estudios críticos del teatro español del siglo XIX» ${ }^{13}$.

En torno a su figura congrega en su domicilio a la «Tertulia literaria del 73», así llamada por coincidir el año de su creación y el número de la casa en que Herrán vivía (Herrería, 73). Desde esta tertulia promueve la creación de una «Academia Cervántica Española», que quedó inaugurada el día 1 de marzo, consagrada, como su nombre indica, a rendir homenaje a Cervantes ${ }^{14}$.

A partir del mes de mayo, y aunque durante algunas semanas solamente, edita El Cantón Vasco, diario republicano, democrático y federal, que da idea de las tendencias políticas e ideológicas de su director.

Pero en este año de 1873 se cierran las puertas de la Universidad vitoriana, el Ateneo comienza una etapa de declive, y la

9 Fermín Herrán, Memoria leída en la Academia Alavesa de Ciencias de Observación el 29 de octubre de 1875. Vitoria, Imp., Lib. y Enc. de los Hijos de Manteli, 1875.

10 R. Becerro DE BengoA, «Don Daniel Ramón de Arrese...», p. 20.

11 E. Velasco López Cano, Crónicas y biografías alavesas..., p. 149.

12 La primera colección, artículos escogidos de la Srta. Grassi, Sr. Hartzenbusch, F. Guerra, C. de Cheste... Vitoria, Imp. de los Hijos de Manteli, 1872.

13 FERmín HerRán, Juicio crítico del drama "Don Francisco de Quevedo", de D. Eulogio Florentino Sanz. Madrid, Lib. de Victoriano Suárez [pero impreso en Vitoria por José Iturbe], 1873. ("Estudios Críticos del Teatro español del siglo XIX»).

${ }_{14}$ De ella me he ocupado en «Fermín Herrán y la Academia Cervántica Española de Vitoria» (en prensa). 
guerra y la defensa del sistema foral consumen los esfuerzos de los vascos.

Lo que resulta sorprendente, como ha quedado indicado más arriba, es que en un momento como este de confrontación bélica, continúe imparable la actividad cultural que despliega Fermín Herrán y su significativa defensa de la figura y de la obra de Miguel de Cervantes, una devoción que se mantiene casi con seguridad desde su estancia en la Universidad de Valladolid.

\section{Fermín Herrán en Valladolid}

Una vez finalizados sus estudios secundarios en el Instituto de Vitoria, donde obtuvo el grado de Bachiller en Artes el 13 de junio de $1868^{15}$, se matricula en la Universidad literaria de Valladolid durante el curso académico 1868-69 para iniciar estudios de Derecho ${ }^{16}$. Los dos cursos siguientes los reparte entre la Universidad libre de Vitoria, la de Oñate, la Central de Madrid y la literaria de Valladolid.

El último año de carrera (1871-72) se matricula como alumno libre en la Universidad castellana. Cursa entonces las asignaturas que le van a permitir licenciarse en las dos ramas existentes en la Facultad de Derecho: la de Civil y Canónico ${ }^{17}$ y la de Administrativo ${ }^{18}$.

15 Así se consigna en su expediente académico. Archivo Universitario de Valladolid: legajos 691-21 y 691-25.

16 En una carta que precede a una reseña bibliográfica publicada en la revista cultural de Valladolid El Museo, Fermín Herrán recuerda el comienzo de sus estudios de Leyes en la Universidad castellana: «Ramiro [Fierlei, seudónimo de Emilio Ferrari]: Hace algunos años, cuando los dos empezábamos a estudiar los inmortales códigos romanos, tuvimos decidido propósito de publicar un Álbum históricolegendario de Valladolid y su provincia. Con este motivo hicimos algunas excursiones, y de feliz recordación son para nosotros, la de Medina del Campo y Simancas». Hermilio [Fermín Herrán], «El Puente Mayor de Valladolid, por E. Feijóo de Mendoza. (Artículo bibliográfico). A mi más querido amigo Ramiro Fierlei», El Museo (Valladolid), núm. 21, 31-III-1872, p. 164.

17 Los ejercicios para la obtención de esta licenciatura los realiza el 17 de junio de 1872, aunque no será hasta el año siguiente (18 de junio de 1873) cuando se le expida el título (Archivo Universitario de Valladolid: legajo 691-21). Parece probable que pensara dedicarse a la docencia universitaria, para la que era indispensable el grado de Doctor (vid. FEDERICo SANZ DíAZ, El alumnado de la Universidad de Valladolid en el siglo XIX (1837-1886). Valladolid, Universidad, 1978, pp. 106-113), pues cursó las asignaturas de doctorado en la Universidad libre de Vitoria entre 1871 y 1873, realizando los ejercicios para la obtención de dicho grado el día 30 de junio de 1873 con la calificación de "aprobado por mayoría» (Archivo Universitario de Valladolid: Libro 426, hoj. 33).

18 Realiza los ejercicios el 22 de junio de 1872 , expidiéndosele el título el 17 de junio de 1873 (Archivo Universitario de Valladolid: legajo 691-25). 
Este curso académico será de gran trascendencia para Fermín Herrán, no sólo por concluir sus carreras universitarias, sino también por otros acontecimientos que tendrán lugar a lo largo de él, significativos en su biografía y de trascendencia para el tema cervantino que nos ocupa.

El 11 de enero de 1872 se inicia en la masonería ${ }^{19}$, muy posiblemente en la logia «Templo de la Libertad» ${ }^{20}$, adoptando el nombre simbólico de "Emilio Castelar», figura por la que sentirá una gran admiración a lo largo de su vida, haciéndose partícipe de sus ideas republicanas.

De republicanos se nutre la redacción de El Museo, semanario cultural que había comenzado su andadura en Valladolid el 12 de noviembre de 1871 de la mano del entonces alférez Eduardo de Ozcáriz, ocupándose de la administración José Ortiz de Pinedo, y de la parte gráfica Rafael Pierrad ${ }^{21}$.

En sus ocho páginas semanales encontramos las firmas de liberales y republicanos federales como José Estrañi, Anselmo Salvá, Albino A. Madrazo, Vicente Colorado, Emilio Ferrari o el propio Herrán, quien comienza su colaboración en el número 10, correspondiente al 13 de enero de $1872^{22}$. Más tarde, y junto a Emilio Ferrari y Albino Madrazo, entra a formar parte de la redacción ${ }^{23}$, de la que se ocupará hasta el último número ${ }^{24}$.

\section{Cervantes en «El Museo»}

A lo largo de los meses de marzo y abril de 1872 se inicia una campaña en El Museo para conmemorar el aniversario de la muerte de Cervantes ${ }^{25}$. Esta campaña culminará con la publicación de un número monográfico fechado a 23 de abril, en el que colaboran Fermín Herrán, Emilio Ferrari, Bernardo López García, Fabián

19 Cfr. Víctor Manuel ARbeloa, «La masonería en Vitoria», Scriptorum Victoriensi, XXII, sept.-dic. 1975 , p. 337.

20 A esta logia pide adscribir la que quiere constituir en Vitoria con el nombre de "Victoria» en 1879 (Cfr. Ídem, p. 333).

21 Vid. Celso Almuiña FernáNDEZ, La prensa vallisoletana durante el siglo XIX (1808-1894), vol. II. Valladolid, Servicio de Publicaciones de la Diputación, 1977, pp. 134-139.

${ }^{22}$ Hermilio, "¡Amor! A la señorita R... P...», pp. 76-77.

23 Número 25, 23-IV-1872.

24 Número 41, 25-VIII-1872.

25 ADOlFo SEIRULlo, «Revista de la semana», El Museo, núm. 18, 10-III-1872, p. 138; suelto en el núm. 23, 14-IV-1872, p. 180; "Tributo a la memoria de Miguel de Cervantes» y Hermilio, "Revista de la semana», núm. 24, 21-IV-1872, pp. 185 y 186. 
Hernández y Anselmo Salvá ${ }^{26}$, y con una iniciativa de su director y redactores: formar una tertulia literaria en la casa en que vivió Cervantes en Valladolid.

\section{El Ateneo literario "La casa de Cervantes en Valladolid»}

Desde 1862, y gracias a las investigaciones del catedrático de Economía política de la Escuela de Comercio de Valladolid don José Santa María e Hita, se tenía la certeza de cuál había sido la casa que habitó Cervantes mientras permaneció en la ciudad castellana ${ }^{27}$. Olvidada su significación por los estamentos oficiales, sus propietarios la tenían alquilada a "particulares de cuyo entusiasmo cervantista no podía formarse un concepto muy favorable, atendidos su condición y estado» ${ }^{28}$.

De esta forma tan pintoresca relata Emilio Ferrari un suceso que puso en guardia a los redactores de El Museo:

Allá por los años del 72 -ya ha llovido... cervantismo desde entonceshabía en Valladolid un grupo de mozalbetes entusiastas y fervorosos por todo cuanto era digno de entusiasmo y fervor; un tanto alborotados y discutidores, curiosos de todo y empeñados siempre en inocentes empresas $[\ldots]$

Pues señor, ello fue que puesta ya por el Municipio la lápida conmemorativa en la casucha miserable que debía convertirse en templo, como dice el Cervantes de Serra, aconteció que un extranjero, de paso en la ciudad fue a dar, como otros tantos, no con las corporaciones oficiales ni con los personajes conspicuos, pero con el inevitable grupillo de adolescentes indocumentados. Mostró en seguida ansia de visitar la que fue vi-

26 Fermín Herrán, «Miguel de Cervantes Saavedra», p. 193; "Cervantes vivo y Cervantes muerto», pp. 196-197; "El Ingenioso Hidalgo Don Quijote de la Mancha, por Miguel de Cervantes Saavedra y los Cervantistas», pp. 198-200. EMILIO FERRARI, "La casa de Cervantes. Meditación», pp. 193-194. Bernardo López García, "Cervantes», p. 194-195. FABIÁN HERNÁNDEZ, "El desembrollo del rucio, o el robo del asno por Ginesillo de Pasamonte. De la obra Bellezas del Ingenioso Hidalgo D. Quijote de la Mancha hasta ahora ocultas para el lector en el original", pp. 195-196. Albino Madrazo, “i...! [poesía]», p. 196. Anselmo SalvÁ, "A Miguel de Cervantes en el aniversario de su muerte», pp. 197-198.

27 ElEUTERIo DíEz RoDRÍGUEZ, «Discurso leído el 25 de diciembre de 1875 por el Sr. D. - referente a la casa que habitó Cervantes en Valladolid por los años de 1603 a 1605, núm. 14 de la calle del Rastro, en la sesión inaugural del salón de reuniones en dicha casa", en La Casa de Cervantes en Valladolid. Sociedad literaria, científica y artística. Composiciones leídas en la sesión inaugural de 25 de diciembre de 1875 y en la de 23 de abril de 1876 aniversario 260 de la muerte de Cervantes. Valladolid, Imp. y Lib. Nacional y Extranjera de Hijos de Rodríguez, 1876, pp. 3-8.

28 ANSElmo SALVÁ, "Los cervantistas vallisoletanos», El Norte de Castilla, 22-V1872, hojs. 1r (cols. 3-5)-1v (col. 1). El texto de la cita en hoj. 1r col. 3. (Véase Apéndice documental). 
vienda del autor de Don Quijote, y uno de los cinco o seis muchachos, creo que el mismo que dirige a usted estas líneas, con la imprevisora audacia de los pocos años, se brindó a acompañarle, encontrándose ambos a poco ante aquel edificio humilde, cuya puerta estaba cerrada a piedra y lodo. Después de aporrearla largo rato, comprendiendo la extrañeza del viajero, asomóse al balcón una mujer desarrapada y sucia.

- ¿Qué deseaban ustedes?

-Queríamos ver la casa de Cervantes.

- Aquí no vive ese señor».

$\mathrm{Y}$ diciendo así la inquilina del venerando templo cerró el balcón refunfuñando.

Mi acompañado era un inglés - que por lo general los protagonistas de estas anécdotas son ingleses-, pero no por esto se dude de la exacta verdad de este relato. Mi hombre se quedó tan escandalizado, como corrido el "cicerone», quien hubiera querido que se le tragase la tierra con lo que iría a dar en el Esgueva, digno sepulcro, según sus lecturas de Góngora y Quevedo en aquella vergonzosa situación ${ }^{29}$.

Abochornados por este suceso, el director de El Museo, Eduardo de Ozcáriz, y sus tres redactores, Albino Madrazo, Emilio Ferrari y Fermín Herrán, envían el día 24 de abril una carta a la prensa con el propósito de instalar una sociedad literaria en la morada cervantina, recuperando así para Valladolid la figura de Cervantes y rescatando un monumento hasta entonces menospreciado, sin duda por la humildad de la edificación ${ }^{30}$.

Desde este momento se suceden las reuniones para la formación del centro cultural dedicado a Cervantes. En la celebrada el día 1 de junio en la casa cervantina, se nombra una junta provisional organizadora, encargada de redactar el reglamento, e integrada por el médico republicano Lucas Guerra, Venancio Castro, Emilio Ferrari, Enrique Macho Quevedo y Fermín Herrán ${ }^{31}$.

A pesar de "algunos sinsabores y no pocas amarguras»" el Ateneo literario "La casa de Cervantes en Valladolid» se inauguró el día 2 de junio en el Ateneo Mercantil, situado en la llamada Casa de las Aldabas. Tras la apertura del acto por parte de Lucas Guerra, presidente interino del Ateneo, intervino su secretario, Anselmo Salvá, dando lectura a la preceptiva memoria. La parte poética estuvo a cargo de José Estrañi, Gregorio Martínez Gómez y Mariano

29 «El centenario del Quijote. Una carta de Ferrari», El Imparcial, 10-XII-1903, p. 1. Carta dirigida a Mariano de Cavia, quien había promovido desde las páginas de El Imparcial (2-XII-1903) la celebración del centenario. (Véase Apéndice documental).

30 "Remitido", El Norte de Castilla, año XVIII, núm. 4623, jueves 25-IV-1872, hoj. 2r, col. 3. (Véase Apéndice documental).

${ }_{31}$ "Gacetillas», El Norte de Castilla, núm. 4630, 3-V-1872, hoj. 2r, col. 3. (Véase Apéndice documental).

32 María [Albino Madrazo], «Ecos», El Museo, año II, núm. 29, 26-V-1872, p. 227. (Véase Apéndice documental). 
del Campo ${ }^{33}$. Cerró la sesión Emilio Ferrari señalando la importancia de Cervantes en la literatura española.

Inaugurado oficialmente el Ateneo, los asistentes se dirigieron a la casa de Cervantes, donde Estrañi volvió a recitar sus famosas quintillas. El diputado republicano por Valladolid don José Muro López felicitó y estimuló a los integrantes de la tertulia, restando importancia a la indiferencia con que el Ayuntamiento de la ciudad había acogido su idea; y don Juan Callejo, secretario de la Diputación provincial, improvisó una composición poética ${ }^{34}$.

Anselmo Salvá en su intervención como secretario del Ateneo literario, expuso los fines del mismo: rescatar la figura y la obra de Cervantes como abanderado de una necesaria regeneración literaria ante el estado de corrupción y confusión en que se encontraba la literatura. Además, señalaba los beneficios que podía aportar un centro cultural como el que en ese momento se inauguraba:

\footnotetext{
Penétrese el proletariado de la necesidad que tiene de ilustrarse, para que no se deje fácilmente alucinar por doctrinas falaces que le exponen a las más tristes contingencias y acuda con resolución a escuchar algo que acaso nunca habrá oído; pues el mayor deseo de esta sociedad, es ser útil al que más necesita las luces de la instrucción.

Sepa también el hombre sabio, que su cooperación en el Ateneo puede producir algunos buenos servicios para las letras y algún provecho para los que quieran servirse de la sociedad como medio instructivo, y no vacile en otorgarla, dando así mayor autoridad y más fuerza a las importantes cuestiones que se ventilen.

El político, el orador, el poeta, el artista, todos hacen falta para consolidar esta obra, cuyo cimiento estamos poniendo, y que, si se cumplen mis deseos y los de todos cuantos me escuchan, llegará a ser un monumento de eterna gloria, que elevará a una altura fabulosa el buen nombre de este ilustrado pueblo ${ }^{35}$.
}

33 José Estrañi, "La casa de Cervantes»; Gregorio Martínez Gómez, "A Miguel de Cervantes»; MARIANO DEL CAMPO, «A Miguel de Cervantes Saavedra». Estas tres composiciones fueron reproducidas en el folletín de El Norte de Castilla entre los días 5 y 8 de junio de 1872. (Véase Apéndice documental). Por su parte El Museo reprodujo las de Estrañi y Martínez Gómez en el número 31, 9-VI-1872, pp. 243244 y $245-247$, respectivamente.

${ }_{34}$ El texto de la misma, así como una reseña del acto de inauguración, puede leerse en El Norte de Castilla, 4-VI-1872, hoj. 1v, cols. 3-5. Fermín Herrán se encargó de hacer dos reseñas de este acontecimiento: "Inauguración del Ateneo literario, La Casa de Cervantes", El Museo (Valladolid), año II, núm. 31, 9-VI-1872, pp. 241-243; "Inauguración de un Ateneo literario en Valladolid en la casa que vivió Cervantes», Crónica de los Cervantistas (Cádiz), año I, núm. 5, 10-VIII-1872, pp. 164-166. (Véase Apéndice documental).

35 «Discurso pronunciado por D. Anselmo Salvá en la apertura del Ateneo literario de la casa de Cervantes, el día 2 de junio de 1872", El Norte de Castilla (Valladolid), año XVIII, nos. 4660-4661, martes 11-VI-1872 (hojs. 1r, cols. 3-5, y 1v, cols. 1-2) y miércoles 12-VI-1872 (hojs. 1r, cols. $3-4 ; 1$ v, cols. 1-5, y 2 r, cols. 1-2). La cita en hoj. 1v, col. 1, del día 12-VI. (Véase Apéndice documental). 
Tras la inauguración del Ateneo, los dueños de la casa, don Fernando Rodríguez y don Eleuterio Díez Rodríguez, quienes, al parecer, la habían cedido ${ }^{36}$, optaron por alquilarla a los socios ${ }^{37}$, que llegaron a ser treinta ${ }^{38}$ :

Los ateneístas reuníanse en tertulia en la casa de Cervantes después de la hora del café, y en aquel saloncillo de la calle del Rastro se discutían, siempre con calor, temas literarios y se reían los muchos donaires y gracias que allí se derrochaban, pues en aquellas amenísimas tertulias había entusiasmo, espontaneidad, algazara y algo de bohemia... ${ }^{39}$.

Desconocemos casi por completo las actividades desarrolladas en el Ateneo, aunque E. Díez Rodríguez señale que «se presentaron trabajos muy dignos» ${ }^{40}$. El Museo, tras dar cuenta de la inauguración del mismo y reproducir las poesías de Estrañi y G. Martínez Gómez ${ }^{41}$, nada vuelve a decir a pesar de haberse comprometido a dedicar una sección a las sesiones celebradas en el mismo ${ }^{42}$.

A finales de noviembre los ateneístas convocaron un certamen literario en el que Emilio Ferrari iba a intervenir con un discurso, y Estrañi y Martín Arroyo iban a leer composiciones poéticas ${ }^{43}$. Sin embargo, "por efecto de las circunstancias» ${ }^{44}$, no llegó a celebrarse.

Estas "circunstancias» a que alude el gacetillero de El Norte de Castilla, no eran, sin duda, las más favorables. La guerra carlista asolaba el Norte peninsular, el rey Amadeo de Saboya estaba a punto de abdicar y se presagiaba el advenimiento de la primera república.

A ello se sumaba la falta de recursos económicos de los ateneístas:

36 Fermín Herrán, «Miguel de Cervantes Saavedra», El Museo, año II, núm. 25, 23-IV-1872, p. 193. (Véase Apéndice documental).

37 "Gacetillas», El Norte de Castilla, 5-VI-1872, hoj. 2r, col. 3. (Véase Apéndice documental).

38 E. DíEz RodríGUez, «Discurso leído...», p. 5.

39 Fidel Pérez Mínguez, La casa de Cervantes en Valladolid. Madrid, Imp. del Asilo de Huérfanos del S. C. de Jesús, 1905, p. 116.

40 E. Díez Rodríguez, "Discurso leído...», p. 6.

41 Número 31, 9-VI-1872. FERMín HERRÁN, «Inauguración del Ateneo literario La casa de Cervantes», pp. 241-243; José EstRañI, «La casa de Cervantes», pp. 243244; Gregorio MARTínez GÓMEZ, "A Miguel de Cervantes», pp. 245-247.

42 María [Albino Madrazo], "Ecos», El Museo, año II, núm. 29, 26-V-1872, p. 227. (Véase Apéndice documental).

43 "Gacetillas», El Norte de Castilla, 26-XI-1872, hoj. 2r, col. 2. (Véase Apéndice documental).

${ }^{44}$ Ídem, 1-XII-1872, hoj. 2r, col. 2. 
Aquel Ateneo, aquellas inolvidables tertulias en la propia casa de Cervantes, apenas duraron media docena de meses, no obstante los esfuerzos de Ferrari, que era quien principalmente daba los mimbres.

$\mathrm{Y}$ aquel grupo de buenos cervantistas abandonó contristado la casa de Cervantes, su templo, volviendo la cabeza para ver de lejos la «joya de Castilla», y siguieron escribiendo versos y leyéndolos en la mesa del café sin olvidar jamás al egregio Manco, pues ellos fueron los que tejieron la primera corona literaria que vio Cervantes sobre sus sienes de inmortal en la humilde y hasta entonces olvidada casa del Rastro de Valladolid ${ }^{45}$.

Pocos años después, en 1875, don Mariano Pérez Mínguez, entusiasta cervantista, rescató la idea del Ateneo fundando la Sociedad literaria «La casa de Cervantes en Valladolid» ${ }^{46}$, en la que colaboraron casi todos los que habían prestado su apoyo a la idea de rescatar la vallisoletana casa de Cervantes en $1872{ }^{47}$.

\section{CARMEN MENÉndez OnRUBia Instituto de Filología \\ C.S.I.C.}

45 F. PÉREZ Mínguez, La casa de Cervantes en Valladolid..., pp. 117-118.

46 F. PÉrez Mínguez, La Casa de Cervantes en Valladolid..., pp. 119-130; La Casa de Cervantes en Valladolid. Sociedad literaria, científica... RAMÓN LEÓN MÁINEz, Cervantes y su época, prólg. Eduardo Benot, tomo I. Jerez de la Frontera, Taller Tipográfico de la "Litografía Jerezana», 1901, pp. 416-418. CASIMIRo GonZÁlEZ García-VAlladolid, Valladolid. Sus recuerdos y sus grandezas. Religión, Historia, Ciencias, Literatura, Industria, Comercio y Politica, tomo I. Valladolid, Imp. de Juan Rodríguez Hernando, 1900, pp. 41-43. IRENE VALLEJo GoNZÁLEZ, «Ambiente literario", en AA. VV., Valladolid en el siglo XIX. Valladolid, Ateneo, 1985, pp. 562-563.

47 Un breve panorama de conjunto de ambos empeños culturales puede verse en MANUel BASAS Fernández, "El Ateneo y la Sociedad literaria, Casa de Cervantes en Valladolid", Santa Cruz (Universidad de Valladolid), curso 1947-1948, núm. 6, pp. $45-50$. 


\section{APÉNDICE DOCUMENTAL}

FERmín HERRÁN, «Miguel de Cervantes Saavedra», El Museo (Valladolid), año II, núm. 25, 23-IV-1872, p. [193].

[...] En esta población existe la casa en que vivió Cervantes el año 1605; y se halla situada en la calle del Rastro, número $14 \mathrm{y}$ antiguamente 11.

Hoy es dueño de ella D. Fernando Rodríguez, entusiasta admirador de aquel ingenio, así como su sobrino D. Eleuterio Díez y Rodríguez, por mediaciones del cual hemos conseguido se nos ceda la casa para formar una tertulia literaria en el mismo cuarto en que Cervantes terminó la primera parte de su no más preciada obra, proyecto que a llevarse a cabo, honrará mucho a Valladolid.

Indiquemos aquí para terminar la gloria que cabría a sus autores, con la formación de una academia o sociedad científica en la casa en que murió Colón.

«Remitido», El Norte de Castilla (Valladolid), año XVIII, núm. 4623, jueves 25-IV-1872, hoj. 2r, col. 3.

Insertamos con gusto el siguiente:

Sr. Director y Redactores de El Norte de Castilla.

Hacía tiempo lamentábamos el que esta población donde han floreado tantos ingenios no posea un centro, eco de sus progresos artísticos y gimnasio donde se prueben y desarrollen las fuerzas intelectuales de los jóvenes que aman la literatura y la poesía.

De una visita a la casa donde vivió el inmortal autor del Don Quijote, ha nacido una idea cuyo germen, contando con la protección de su dignísimo periódico, puede desarrollarse para honra y gloria de esta ilustrada capital que albergó en su seno al Príncipe de los ingenios.

La instalación de una sociedad literaria en la pobre habitación donde el eco repitió algún día el acento inspirado de Cervantes, es nuestro propósito, y para que pueda llevarse a la práctica es necesario que vuestra cooperación nos preste fuerza, que vuestro genio nos anime y que vuestra autorizada palabra se haga escuchar entre los amantes de la literatura patria. A todos estos así como a vosotros os convocamos a una reunión preparatoria que tendrá lugar en la citada casa, (Rastro, 14), el viernes a las seis de la tarde.

Eduardo Ozcáriz.-Emilio Ferrari.-Fermín Herrán.-Albino Madrazo.

Abril, 24. 
«Gacetillas», El Norte de Castilla (Valladolid), año XVIII, núm. 4626, domingo 28-IV-1872, hoj. 2r, col. 2

Para hoy. Por efecto del mal tiempo que en la tarde del viernes tuvimos, no pudo verificarse la reunión a la hora citada en la casa del inmortal Cervantes, de los literatos y aficionados a las letras de esta ciudad, habiendo determinado trasladarla para hoy a la una de la tarde en la sala alta del café Suizo.

«Gacetillas», El Norte de Castilla (Valladolid), año XVIII, núm. 4627, martes 30-IV-1872, hoj. 2r, col. 2

Loor al genio. Con el laudable objeto de llevar a efecto el pensamiento por todos aplaudido de establecer una Tertulia literaria en la casa misma en que habitó el gran Cervantes, se ha acordado recoger cuantas inscripciones a dicha sociedad quieran hacerse por los amantes de la literatura española en las oficinas de la imprenta en que se publica El Museo y El Norte de Castilla, situada en la plazuela de las Angustias, y de la propiedad de los señores Gaviria y Zapatero.

«Gacetillas», El Norte de Castilla (Valladolid), año XVIII, núm. 4630, viernes 3-V-1872, hoj. 2r, col. 3.

Tributo a Cervantes. Antes de ayer en la casa donde vivió este inmortal genio, se reunieron los individuos que han de componer la Tertulia literaria, dedicada a la memoria del autor de Don Quijote, se nombró una junta provisional organizadora, encargada de redactar un reglamento, y terminado convocar a junta general, para constituir definitivamente dicha Tertulia.

La junta provisional la componen los Sres. D. Lucas Guerra, D. Venancio Castro, D. Emilio Ferrari, D. Fermín Herrán y Enrique M[acho] Quevedo.

Hora es ya que en Valladolid hubiera una asociación de esta naturale$\mathrm{za}, \mathrm{y}$ no dudamos que todas las personas amantes de las bellas letras, prestarán su apoyo y protección a la naciente Tertulia.

"Gacetillas», El Norte de Castilla, año XVIII, núm. 4635, jueves 9-V-1872, hoj. 2r, col. 4.

No olvidarlo. Esta tarde a las cuatro tendrá lugar la reunión de todos los inscritos a la Tertulia literaria que piensa establecerse en la casa del 
inmortal Cervantes con objeto de dar lectura al reglamento orgánico de la misma, y discutir sus artículos para su completa constitución.

ANSElmo SALVÁ, «Los cervantistas vallisoletanos», El Norte de Castilla (Valladolid), año XVIII, núm. 4644, miércoles 22-V-1872, hojs. 1r (cols. 35)-1v (col. 1).

Nuestro apreciable amigo D. Anselmo Salvá, nos remite el siguiente artículo, sobre la sociedad cervantina establecida nuevamente en Valladolid, para que le insertemos íntegro a fin de dar a esta idea más publicidad.

Dice así:

\section{LOS CERVANTISTAS VALLISOLETANOS}

Bajo el título de La casa de Cervantes, se ha establecido en esta población un Ateneo literario, que quedará situado en la misma casa donde habitó aquel peregrino ingenio.

Próximo el día en que ha de celebrarse con toda solemnidad la inauguración de este centro de las bellas letras, que tan urgentemente reclamaban la ilustración y el grado de cultura a que ha llegado la capital de Castilla la Vieja, nos permitiremos decir cuatro palabras a nuestros lectores, para que se penetren de la gran importancia que dicha sociedad está llamada a tener, si el público vallisoletano, y el elemento joven sobre todo, la prestan su decidido apoyo, venciendo la apatía que ha hecho fracasar empresas de parecida índole.

El solo nombre de Cervantes hace comprender desde luego que se trata de rendir homenaje al más grande, al más ilustre de los escritores españoles, cuya fama se hace más brillante cuantos más años transcurren.

Vergüenza grande es para Valladolid que un ayuntamiento, sus corporaciones científicas y sus centros literarios hayan visto con indiferencia la casa que sirvió de morada al noble manco de Lepanto, habitada por particulares, de cuyo entusiasmo cervantista no podía formarse un concepto muy favorable, atendidos su condición y estado. ¡De cuántas formas no podía haberse utilizado monumento tan grande! Por desgracia ha pasado mucho tiempo sin que ningún castellano, ningún español y solamente algunos extranjeros, fijasen su vista en la humilde morada, que en otro país hubiera sido causa de serias disputas, al tratar de su adquisición; pero afortunadamente hoy no continúa olvidada. Unos jóvenes que cultivan las letras con felicidad y que profesan a Cervantes todo el respeto que merece, se rebelaron contra la apatía en que con respecto a tal punto había permanecido este público, y determinaron hacer suya a toda costa la casa en cuestión, para establecer en ella una sociedad digna de esta capital y del nombre que debía patrocinarla.

Estos jóvenes que son los redactores de El Museo, han visto logrado su objeto, y secundada su idea por personas de autoridad y distinción; es 
decir, que la sociedad está formada bajo felices auspicios y que puede esperarse su pronto engrandecimiento.

Nosotros que somos los cervantistas más llenos de entusiasmo, a la vez que más desprovistos de títulos meritorios, creemos sinceramente que Valladolid está de enhorabuena; porque sólo el hecho de haberse puesto al nivel de poblaciones como Barcelona, Málaga, Sevilla, Cádiz, Valencia y otras, realza bastante a los castellanos, que desde hoy contarán con un centro de donde pueden resultar considerables beneficios intelectuales.

Nadie desconoce las provechosas conveniencias que produce el movimiento literario constante y bien dirigido. La instrucción se propaga insensiblemente; el estímulo para el estudio se desarrolla sin remedio y con el concurso de las personas ilustradas, pueden dilucidarse cuestiones importantes.

Además, las sociedades de esta naturaleza, cuando se ven favorecidas por el éxito, acaban por crear bibliotecas, escuelas y otros medios instructivos que producen beneficios patentes a las clases trabajadoras, tan necesitadas de ciertos conocimientos muy útiles para el más satisfactorio estado de la sociedad en general.

Estos resultados para todos son halagüeños, y el que no ayuda a su propagación, ni es digno de habitar un pueblo culto, ni da pruebas de buen sentido.

Mediten mucho los castellanos sobre este asunto y se convencerán de que están en la obligación de proteger la sociedad cervantista por honor a su nombre y por amor a su. patria. Las sesiones de este Ateneo ofrecerán sin disputa irresistible atractivo para toda clase de personas que de ellas pueden obtener algún provecho, a la par que alguna distracción.

Los debates políticos siempre estériles, siempre molestos, siempre origen de amargos disgustos, se ven generalmente favorecidos por una concurrencia numerosa; $¿ y$ no han de estar más concurridas unas conferencias literarias y artísticas, en que solamente se tratará de las concepciones más bellas de los grandes hombres, del conocimiento de las cuestiones que más interesan al corazón y de los dulces y tranquilos goces que proporciona la poesía? Necedad insigne sería renunciar a ver de mil maneras comentariados los más notables pensamientos de Cervantes; a recrearse con el sentimiento de los puros afectos que despierta el estudio de los poetas más eminentes y a educar las facultades estéticas con el examen de los tesoros de las letras y de las artes.

Atendidas estas consideraciones, creemos firmemente que el público vallisoletano acudirá presuroso a dar vigor a la sociedad literaria de la casa de Cervantes, y esperamos por lo tanto que su inauguración solemne, que se verificará probablemente en el salón del Ateneo Mercantil, se verá concurrida por infinitas personas, entre las que deberán figurar nuestras autoridades y los hombres de distinción en todos los ramos del saber humano.

También el bello sexo ha de tener un lugar preferente en la solemne fiesta; pues nadie mejor que quien inspira casi siempre las ideas más hermosas de la inteligencia del hombre, quien concreta en sí la belleza, objeto principal de la literatura y de las artes, puede dar esplendor y vida a 
una sociedad que nace para cultivar un terreno en que crecen las más lozanas y fragantes flores del alma.

Citaremos para terminar el ejemplo de Valencia, de la hermosa Valencia, allí con motivo del aniversario de la muerte del autor del Quijote, se ha celebrado recientemente una sesión en el Ateneo, que ha merecido el elogio de toda España; allí han estado las autoridades, el profesorado, los artistas, los literatos, los escolares, toda la población; allí ha tenido su representación el bello sexo en las más lindas e ingeniosas valencianas; allí, en fin, han honrado las letras y se han honrado a sí mismos.

Aspiremos siempre a ser más; contentémonos en todo caso con ser tanto; pero nunca consintamos ser menos.

Teniendo en cuenta todo esto, nos atrevemos a asegurar que la inauguración de la sociedad cervantista será un acontecimiento fastuoso y que Cervantes desde el cielo sonreirá a este pueblo, que se dispone a enaltecer tanto su preclaro nombre.

¡Honor y gloria a la sociedad cervantista de Valladolid!

María [Albino MADrazo], «Ecos», El Museo (Valladolid), año II, núm. 29, 26-V-1872, p. 227.

[...] ¡El Ateneo! Esta palabra representa esfuerzos, sacrificios, dificultades, obstáculos y gloria.

Sólo Cervantes, sólo la literatura patria merecen estos trabajos que cuestan algunos sinsabores y no pocas amarguras.

Ya está realizado el deseo de los amantes de las letras; ya la aspiración está cumplida; ya es un hecho la esperanza; ya Valladolid no llorará la pérdida del Liceo donde nacieron el primer lírico y el primer publicista de nuestra época.

Ahora sólo falta pensar, bastante se ha sentido, bastante tiempo se ha callado. Llega la hora en que los labios cantan los misterios del alma y los recuerdos de su vida.

El Museo, a quien se debe el primer paso, la iniciativa, el pensamiento, el deseo y el primer esfuerzo, se ocupará en una sección de todo lo que ocurra en las sesiones del Ateneo para regocijo de Cervantes y gloria de Castilla.

Hoy sólo cumple mostrar su profunda gratitud a todas las personas sumamente respetables por su ciencia, por su talento, por su nombre y por su amor, que han apoyado, protegido y defendido nuestro pensamiento, tanto aquí como en la Corte.

El Domingo, la casa de Cervantes se cubrirá de galas, y el genio del mundo se alegrará en los cielos. Ese día será la inauguración. En ella se leerán una Memoria de Salvá, una composición de Estrañi... y... muchas cosas que perderían su mérito si se dijeran. 
"Ateneo cervantista», El Norte de Castilla (Valladolid), año XVIII, núm. 4654, martes 4-VI-1872, hoj. 1v, cols. 3-5.

El domingo fue un día de gloria para Valladolid.

Según oportunamente manifestamos, a las doce de dicho día, que siempre recordaremos con júbilo, dio principio el acto solemne de la inauguración del Ateneo Cervantista. Multitud de personas ocupaban el espacioso local destinado para este objeto, entre las que se veía también al bello sexo representado por simpáticas y graciosas señoras y señoritas, amantes de la literatura patria.

Ocupaban la presidencia el Sr. Guerra (D. Lucas), D. Anselmo Salvá, secretario, el Sr. Llana, vocal, y los representantes de la prensa.

El Sr. Guerra como presidente interino del referido Ateneo, usó de la palabra, manifestando al numeroso público con frases y pensamientos dignos todos de una persona ilustrada, el objeto de esta sociedad, que, aunque nacía pobre como pobre fue el célebre escritor del siglo XVI, se hallaba con fuerzas suficientes, y que ayudados todos los que la componían por el entusiasmo grandioso de reanudar la memoria y recordar siempre los hechos gloriosos del famoso batallador de Lepanto y las hazañas del prisionero de Argel, será algún día, cuando menos, un merecido tributo que los hijos de Castilla han querido dedicarle para que se consigne en las páginas de la moderna historia.

Se procedió inmediatamente por el secretario a dar lectura de una erudita y bien coordinada Memoria, en la cual se encontraban pensamientos muy sublimes y concepciones magníficas que merecieron grandes y nutridos aplausos del ilustrado público.

El Sr. Estrañi, célebre poeta, joven de una imaginación privilegiada, y en mayor grado, entusiasta de las obras de Cervantes, estaba encargado de leer en aquel acto una composición poética dedicada a la memoria del autor del Quijote.

Jamás nuestra torpe pluma se atrevería a comentar las ideas que el Sr. Estrañi emitió en los razonados y sublimes pensamientos de la referida composición. Cada frase de ella necesita, aun para las imaginaciones más expertas, meditarse bien para comprender lo grande, lo majestuoso, de cuantos pensamientos en ella emite. Sépanlo nuestros entusiastas cortesanos que con orgulloso cántico prodigan elogios a los poetas de Madrid sin acordarse que también en las provincias se encuentran notabilidades en literatura y hombres que, como el señor Estrañi, son dignos, muy dignos de figurar en primera línea con los poetas más reputados de España.

A continuación se leyeron por D. Mariano Campo y D. Gregorio Martínez otras poesías que fueron, como la del Sr. Estrañi, sumamente aplaudidas; y para que nuestros lectores puedan apreciar el mérito de ellas, las insertaremos mañana en la sección del folletín.

El presidente concedió la palabra al Sr. D. Emilio Ferrari, redactor de El Museo, el cual, con elegantes y poéticas frases manifestó de una manera admirable las conquistas y los méritos literarios que nos ha legado Cervantes; fue interrumpido varias veces por los aplausos que el ilustrado 
público le prodigaba; y concluyó nuestro distinguido compañero dando gracias a las señoras y señoritas que honraron aquel acto con su presencia; a la prensa por el decidido apoyo que ha prestado para la realización de este Ateneo y a cuantas personas directa e indirectamente contribuyeron a los mismos fines.

Por nuestra parte nos congratulamos sinceramente y enviamos a los iniciadores de esta idea, el director y redactores de El Museo, nuestro más cordial parabién, lo mismo que a cuantos secundaron y acabaron de realizarla, pues como dice un sabio, tanta gloria merece el que imagina una idea, como el que la propala y termina.

Finalizado el acto solemne de la inauguración, se dirigieron todos o la mayor parte de los concurrentes a la humilde morada que habitó el inmortal Cervantes, en la calle del Rastro, núm. 14. Recorridas las estancias de aquel sagrado recinto en donde parece que el corazón se hallaba oprimido de tanta dicha, el poeta don José Estrañi, a petición de muchas personas, dio lectura otra vez con enérgica frase y entusiasmado acento a la sentida poesía, siendo estrepitosamente aplaudido al final de cada quintilla. En seguida el diputado a Cortes por esta ciudad, D. José Muro López, a instancia de varios amigos, hizo uso de la palabra, y con esa elocuencia indisputable que posee, manifestó la alegría que en aquellos momentos embargaba su alma, al tomar parte en un acto tan grande como sublime. Expuso con la galanura del lenguaje más perfecto, que desde el exterior del edificio al rincón más escondido de la casa, revelaba todo ese modesto y miserable trato con que siempre viven los genios de la ciencia y del saber, como el ilustre D. Miguel Cervantes Saavedra. Se lamentó con sobrada razón el Sr. Muro, de la apatía con que las autoridades y corporaciones locales habían mirado el acto de la inauguración, sintiendo que éstas no le hubiesen concedido la importancia que merecía, puesto que al contribuir con su apoyo en obsequio del establecimiento del Ateneo Literario, rendían culto y admiración a la ciencia y a la literatura, genuina y noblemente personificada en el autor del Quijote, asombro de las naciones más civilizadas. Aplaudió el celo de los amantes de las letras, que con frenético afán y constantes desvelos habían logrado realizar la instalación de dicha Tertulia, y les aconsejó que siguieran con igual fe que hasta aquí, sirviéndoles de estímulo la gloria que por tan solemne acto les correspondía. Al mismo tiempo les dijo que la indiferencia demostrada por las autoridades y corporaciones invitadas oportunamente al efecto, se tornaría en apoyo y protección, toda vez que se hallan compuestas de personas ilustradas. Así también lo creemos nosotros.

Últimamente, el secretario de la Excelentísima Diputación provincial, D. Juan Callejo, con un lenguaje puramente filosófico, se hizo partícipe del júbilo que reinaba en el ánimo de todos, invocando el nombre del esclarecido cautivo de Argel y recitando por final la siguiente improvisación poética, que le valió nutridos aplausos:

«¿Qué importa, nos dirán, para la ciencia

Del sabio la morada? ¿Al fetichismo

Torpe culto rendís? ¿El fanatismo

Preside de los doctos la conciencia? 
Ateos negarán la trascendencia

Del saber, la virtud y el heroísmo.

Cuando el hombre que muere, en su organismo,

Deja a los vivos su divina esencia.

Éter sutil, espíritu impalpable,

¿Dónde su aspiración será más bella,

Más eficaz, sublime y estimable

Que donde el sabio señaló su huella?

¡Aquí inspiraos, de su gloria amantes,

En la modesta Casa de Cervantes!»

Quedó, pues, abierto el local, y desde aquel momento se declaró establecido el Ateneo Literario.

El Norte de Castilla (Valladolid), año XVIII, nos. 4655-4658, miércoles 5VI-1872-sábado 8-VI-1872, folletín.

Poesías dedicadas al inmortal vate Don Miguel Cervantes Saavedra, leídas el día 2 de mayo de 1872 con motivo de la inauguración del Ateneo Literario, establecido en su misma morada. Valladolid, Imprenta y librería de Gaviria y Zapatero, Sucesores de Roldán, 1872 [portada, 5-VI-1872, folletín, hoj. 1r.]

Poesías. A la memoria de Cervantes [portadilla, 5-VI-1872, folletín, hoj. 1r.]

JosÉ ESTRAÑI, «La casa de Cervantes»

Sublimes glorias refleja

como ráfagas el astro

que vida en las plantas deja,

una casa humilde y vieja

en el Campillo del Rastro.

No es que sus destellos puros

el arte con sus cinceles

dejara en mármoles duros,

ni que dominen sus muros

agujas y chapiteles. [p. [5], 5-VI, hoj. 1r]

No es que sus techos preciados

ostenten brillantes frescos,

ni magníficos calados

ni ricos artesonados,

ni ingeniosos arabescos.

No es albergue señorial, ni brilla sobre el portal

de vana pompa desnudo,

el churrigueresco escudo

de algún señor principal. 
Es una pobre morada de irregular ventanaje y pared desnivelada; derruida la fachada, carcomido el maderaje.

Injurias muestran sus cuevas del tiempo, en huellas impuras, que son de su fin las pruebas; las ventanas, sin fallebas; las puertas, sin cerraduras.

Albergue que no señala [p. 6, 5-VI, hoj. 1v] ni aun el indicio más leve del arte que el cielo escala ni más adorno ni gala que una inscripción y un relieve.

$Y$ ésta que glorias refleja como ráfagas el astro que vida a las plantas deja, aún existe pobre y vieja en el Campillo del Rastro.

Dejad que de ella no brote fulgor de oro y de diamantes mientras conserve este mote: ¡AQUÍ SE HOSPEDÓ CERVANTES EL GRAN AUTOR DEL QUIJOTE!

¡Vedla bien! En su pobreza la hizo el ingenio mercedes que el mundo a notar empieza. ¡Grabado está en sus paredes el sello de su grandeza!

De esta morada la nave guardó al ingenio fecundo [p. 7, 6-VI, hoj. 1r] a la par festivo y grave, cuyo nombre ya no cabe en los ámbitos del mundo.

¡Miradla! Esos aposentos aún atestiguan sus chanzas, sus penas, sus pensamientos, sus placeres, sus tormentos, sus dudas, sus esperanzas.

¡Ahí sintió el noble poeta quizá la primera herida que el alma del hombre inquieta! ¡Ahí vino a turbar su vida la aventura de Ezpeleta!

Pronto quizá sólo quede de ella un recuerdo en la historia; ipero no a los siglos cede! 
¡Es que soportar no puede el peso de tanta gloria!

De ella con destellos puros el genio que el mundo aclama cuajó sus cercos oscuros. [p. 8, 6-VI, hoj. 1v] ¡Cada grieta de esos muros es un pregón de su fama!

¡No es palacio y maravilla no es templo y allí se reza; no es roca y al mundo humilla; no es del arte una riqueza y es la joya de Castilla!

Más sus grandezas parecen y más puro su arrebol según los años fenecen, como las sombras que crecen cuanto más se aleja el sol.

¡Cervantes! En la vivienda que tu recuerdo engalana de su entusiasmo en ofrenda, hoy abre noble contienda la juventud castellana.

Bajo los techos que un día quizá vieron tu quebranto, resonará su armonía [p. 9, 6-VI, hoj. 1v] ¡Cobíjales bajo el manto de tu rica fantasía!

Honran así tu memoria en la casa que les cedes; y aspiran a la victoria de colgar en sus paredes los trofeos de tu gloria.

¡Cervantes! ¡Titán glorioso de ingenio grande y fecundo, cuyo talento asombroso dejó un rastro luminoso sobre la esfera del mundo!

¡Gloria de España inmortal, que de la muerte venciendo la arrogancia natural verás los siglos cayendo al pie de tu pedestal!

Oye mi atrevido ruego que con mi intención escudo, y perdona si no llego ante tu presencia mudo [p. 10, 6-VI, hoj. 1r] ante tu grandeza ciego. 
Puso en mi mano el laúd para cantarte loores la pinciana juventud, ¡La sombra junto a la luz! ¡La niebla entre resplandores!

$\mathrm{Y}$ yo que odiando el marasmo contemplo tu altiva gloria, que es del universo pasmo, pido para su entusiasmo el aplauso de la historia.

A ellos, cuya fe contemplo se deben estos instantes; y a su generoso ejemplo, el que se convierta en templo la morada de Cervantes.

¡Y templo es ya que refleja las puras glorias de un astro que eterno fulgor nos deja, esa casa humilde y vieja en el Campillo del Rastro! [p. 11, 6-VI, hoj. 1r]

Gregorio Martínez Gómez, «A Miguel de Cervantes»

Era de nuestra España el bello día lanzado el sarraceno

de su imperial Granada, allá dentro del África gemía.

La tierra adivinada por Cristóbal Colón, en nuestro suelo iba rico metal atesorando; el nieto de Isabel y de Fernando a su genio potente uniendo el brazo ibero [p. [13], 7-VI, hoj. 1r] tal vez pensó en su mente poder avasallar el mundo entero; y de Felipe el vasto poderío guardado con empeño, era ocasión para el guerrero brío de grata vida y porvenir risueño, en tanto que las musas preparaban con delicadas manos, coronas que ciñeran las frentes de los vates castellanos.

En tan brillante edad, gentil mancebo de ambición noble henchido,

las armas y las letras adoraba, y en busca del laurel apetecido a luchar y a escribir se preparaba. ¿Cuál, insigne Cervantes,

fue el premio de tu afán?... ¡Ah! La fortuna 
te volvió el rostro, impía,

"desde el primer sollozo de la cuna»,

y en su tenaz porfía

disipó tus más bellas ilusiones

y fuiste, cual barquilla entre aquilones,

que rota queda al fin y destrozada

y en las amargas olas anegada.

Tú, de Lepanto en la tremenda hora

que en ansias vivas contemplaba el mundo, [p. 14, 7-VI, hoj. 1v]

y a do corriste con marcial anhelo,

postrado por la fiebre abrasadora

ves con dolor profundo

que heroico morir te niega el cielo;

el ruido y vocería del combate

rugen sobre tu frente,

del hondo mar escuchas los bramidos

$\mathrm{y}$ de tu pecho ardiente

no pudiendo calmarse los latidos,

subes en un arranque soberano

contra suerte tan fiera,

con débil cuerpo y temblorosa mano

buscando el primer puesto en la galera...

Tras largo luchar, la patria amada,

aquella que en el orbe no cabía,

quieres de nuevo ver, bien confiado

que dulces distinciones guardaría

a quien por ella había

su sangre, con orgullo, derramado

Mas jay! cruel destino

se interpone otra vez en tu camino.

Ese antiguo invasor de nuestra tierra

ese, de nuestra fe rudo adversario,

que en continuada guerra

mil veces besó el polvo, temerario,

ora, corriendo el mar, traidor pirata, [p. 15, 7-VI, hoj. 1v]

el Sol de tu ventura deteniendo,

tus ambiciones mata,

y con bárbaro ultraje

la fe y la humanidad escarneciendo,

su homicida coraje

al grillo y la cadena

y cruel cautiverio te condena.

Seis años de martirios no lograron

abatir un momento

su compasivo y generoso aliento:

y si el airado moro

en su codicia sórdida alcanzara

de júbilo y de gracias el tesoro

que tu mente encerrara,

víctima de su saña

murieras para el mundo y para España.

¿Dónde riquezas encontrar bastantes

para comprar con oro

el peregrino ingenio de Cervantes? 
Cansado de la guerra

de la que sólo heridas le quedaron, vuelve el rostro a las musas

y las musas también le desdeñaron.

Hasta el teatro llega,

y ve, no con dolor, que en el teatro

reina solo y feliz Lope de Vega. [p. 16, 7-VI, hoj. 1r]

¿Qué senda tomará?... Cubra el olvido

los años de amargura

que aquel pecho leal y agradecido

atravesó infeliz... Su suerte dura

y tristes desengaños,

le hacen por vía extraña y espinosa

buscar un galardón, y nuevos daños

su honra sin mancilla

recoge en su tarea fatigosa;

preso en Argamasilla,

preso en Valladolid, preso en Sevilla,

comienza al fin en la mansión oscura

el libro incomparable

que gloria para siempre le asegura.

Cruja la envidia aceda,

con doblado furor su negro diente,

salga a luz insolente

la parodia infeliz de Avellaneda;

todo será despojos en el camino

de su ingenio divino,

que inmenso desplegándose, derrama

por do quiera la luz y la alegría,

cual la fecunda Dama

del encumbrado luminar del día.

Los pueblos han luchado por su cuna,

el docto anhela esclarecer su historia, [p. 17, 7-VI, hoj. 1r]

a la dulce memoria

de su genio y su mísera fortuna,

se va alzando uno y otro monumento

que contempla el espíritu embebido;

de Guttenberg el prodigioso invento

su libro ha repartido

de España en los rincones

y de la tierra en todas las naciones.

Sus páginas encuentran por do quiera

dulcísima acogida...

¿Quién con tal porvenir no apeteciera

oscura muerte y desgraciada vida?...

Tus restos se han perdido... Mas tu sombra

vaga doquiera que el talento brilla,

y hoy te aclama y te nombra

su protector la Corte de Castilla

Por ti se juntarán los que al Parnaso

se dirigen, las huellas

siguiendo de Rioja y Garcilaso,

y tú serás un mágico amuleto

para todo el que imite 
a Calderón y a Lope y a Moreto,

y del renombre nacional celoso

se cuide y se complazca

en lo bello, sublime y generoso.

A mí en tanto; perdido [p. 18, 7-VI, hoj. 1v]

en las orillas del humilde Esgueva

en donde tú viviste desvalido,

allá en la tarde divisar me agrada,

cuando el sol entre nubes se ha escondido

la que fue tu morada,

y sumergirme en plácida tristura,

y murmurar cuando tu sombra evoco;

¡Si fuese cual la tuya mi locura

quiera el cielo también volverme loco! [p. 19, 8-VI, hoj. 1r]

M. DEL CAMPO, "A Miguel de Cervantes Saavedra»

I

Yace envuelta en las sombras del pasado

una admirable y peregrina historia,

de un varón eminente y desgraciado

que hoy recuerda encantada mi memoria.

Por más que el tiempo intente despiadado

borrar los timbres de la humana gloria, [p. [20], 8-VI, hoj. 1v]

no alcanzará los fines de su intento,

pues eterna es la luz y el pensamiento.

\section{II}

Así, Cervantes, cuya historia evoco,

cuyo talento mágico y profundo

hizo que un día le creyeran loco

por copiar las locuras de este mundo;

a través de los tiempos él tampoco

ha de morir, su genio sin segundo

cual iris tras las roncas tempestades

alumbrará por siempre a las Edades.

III

Él con su pluma de brillantes y oro impregnado en crueles sinsabores,

dio al mundo, de lecciones gran tesoro,

más que ostenta de abril el prado flores:

él sufrió desengaños sin desdoro, [p. 21, 8-VI, hoj. 1v]

él truncó de la suerte los rigores

¡Y Cervantes fue, en fin, loco y mendigo,

burlando tanto afán, tanto castigo!...

IV

Del tronco de los héroes gigantes nació la hermosa y esplendente rama del príncipe inmortal, del Gran Cervantes, 
que así lo anuncian con perpetua fama desde aquellas regiones más distantes en que el sol deja ver su pura llama, hasta los apartados hemisferios donde espira la luz entre misterios.

\section{$\mathrm{V}$}

Si ayer el mundo le forjó cadenas, hoy a su gloria inmensa eleva altares; [p. 22, 8-VI, hoj. 1r] si ayer gustó la hiel de amargas penas en nuestros ricos y felices lares, mire su augusta sombra cuán serenas hoy las horas caminan sin pesares, y en lugar de la envidia y el encono a su grandeza se levanta un trono. [p. 23, 8-VI, hoj. 1r]

«Gacetillas», El Norte de Castilla (Valladolid), año XVIII, núm. 4655, miércoles, 5-VI-1872, hoj. 2r, col. 3.

Lo agradecemos. Con orgullo participamos a nuestros lectores que don Eleuterio Díez, dueño de la casa-morada que habitó el autor del idioma castellano, el inmortal Cervantes en esta capital, ha cedido por un módico precio el local de la misma, a los que componen la sociedad del Ateneo Literario, con el laudable y generoso objeto de ver tan inapreciable joya, ocupada por los amantes de las ciencias y de la literatura. Este rasgo enaltece la pasión que dicho dueño y demás familia manifiestan por la conservación de aquella respetable finca.

«Gacetilla», El Norte de Castilla (Valladolid), año XVIII, núm. 4659, domingo 9-VI-1872, hoj. 2r, col. 3.

No olvidarse. Hoy a las doce se reúnen en la Casa de Cervantes los socios que el último domingo inauguraron el Ateneo científico-literario. En esta reunión se revisará el reglamento y se nombrará la junta definitiva.

FERMín HERRÁN, «Inauguración del Ateneo literario, La Casa de Cervantes», El Museo (Valladolid), año II, núm. 31, 9-VI-1872, pp. 241-243.

Esta es una de las veces que más satisfacción siento al tomar la pluma para dirigirme al público, pues voy a darle cuenta de un acontecimiento extraordinario, que promete a Valladolid grandes días de gloria, y que 
prueba la estimación que nuestra capital profesa a los que procuran por todos los medios su mayor grado de prosperidad.

Me refiero a la solemne apertura del Ateneo literario, La casa de Cervantes, que se verificó el pasado Domingo [2 de junio] en el salón del Ateneo Mercantil, con una brillantez sorprendente.

A la hora anunciada - doce de la mañana [...]

Subieron a ocupar la mesa el presidente de la Sociedad, D. Lucas Guerra, el secretario D. Anselmo Salvá y los representantes de la prensa local $[\ldots]$

El presidente abrió el acto pronunciando uno de los más concienzudos discursos que han salido de sus labios; en él manifestó el objeto de la Sociedad por medio de frases escogidas y pensamientos muy notables; se extendió en consideraciones filosóficas acerca de las utilidades que reporta el cultivo de la literatura en centros creados al efecto, y solicitó, por último, el apoyo de todas las clases para sostener y fomentar el Ateneo Cervantista [...]

Enseguida se levantó el secretario, Sr. Salvá, y leyó la memoria que le había encomendado la Junta organizadora del Ateneo. En ella hizo primeramente, con sencillez y claridad, una historia de los trabajos hechos para la realización de la idea y después adujo bien meditadas consideraciones al efecto de probar que en esta época, como en el siglo XVI, hace falta un libro que destruya completamente el estragado gusto literario que domina en la actualidad [...]

He aquí cómo exponía el tema de su discurso:

«En muchas ocasiones se ha sentido la necesidad apremiante de un genio bastante autorizado para imponer al mundo sus doctrinas, cortando las funestas tendencias marcadas en los más hábiles cultivadores de las letras y destruyendo opiniones y teorías incompatibles con el buen gusto que debe presidir a todas las concepciones del ingenio humano.

Pero ahora que se manifiestan en casi todas las obras cualidades y condiciones brillantes al parecer, pero en realidad perniciosas, las cuales sin un oportuno correctivo, sin una inteligencia bastante ilustrada para juzgarlas y bastante atrevida para rechazarlas, van poco a poco formando parte constitutiva del carácter general de la literatura, con harto menoscabo de la belleza y no menos perjuicio del público, la falta de una inteligencia superior, reformista por esencia, es una desgracia que algún día lloraremos amargamente».

Esta verdad reconocida por todos es precisamente una de las causas que han producido la instalación de la sociedad cervantista: ya que no exista un hombre que por sí solo sea capaz de innovar el carácter de nuestra literatura, bueno será que la unión de todos los que la desean, intente propagar la idea de su necesidad y se esparce [sic; esfuerce] por alejar de nosotros las malas tendencias que se notan y que por móviles harto tristes no han sido combatidas tan rudamente como merecen [...]

Después del trabajo del Sr. Salvá, leyó el Sr. Estrañi, poeta bien conocido del público vallisoletano, una brillantísima composición que fue calurosamente aplaudida [...]

Los señores Martínez Gómez y Campo leyeron también composiciones que obtuvieron también grandes aplausos. La del primero es una biogra- 
fía del inmortal Cervantes, salpicada de pensamientos originales y bellos y de un estilo muy agradable. La del segundo, bastante menos concienzuda, tenía belleza en la forma, a pesar de que según mis noticias fue escrita precipitadamente.

El Sr. Ferrari remató dignamente la fiesta, pronunciando un magnífico discurso con gran soltura, elegantes maneras, en cuyo transcurso y al tratar con muchísima novedad de todo lo que España y las letras en general deben al ilustre Manco de Lepanto, dio muestra de sus vastos conocimientos de filosofía, y de su poderosa imaginación haciendo descripciones encantadoras, comentarios discretísimos y atinadas deducciones.

Nos parece inútil decir que fue interrumpido diversas veces por los aplausos del público y que al final éste le colmó de plácemes y felicitaciones.

Una vez oído este brillante discurso, el Sr. Presidente invitó a todas las personas presentes para decir o leer algo en honor de Cervantes, y como no hubiese ninguna que lo hiciera, declaró abierto el Ateneo literario y dio por terminado el acto de la inauguración.

Pero faltaba aún una segunda sesión tan interesante y amena como la que acabamos de describir y ésta se celebró en la misma casa donde habitó el insigne autor del $D$. Quijote. Allí se trasladaron desde el Ateneo Mercantil algunas señoritas y casi todas las demás personas, impulsadas por el noble deseo de visitar aquellos recintos sagrados, de los que, cada grieta, como decía muy bien el inspirado Estrañi, es un pregón de la gloria de Cervantes. La composición de aquel distinguido vate, se oyó de nuevo entre aquellas paredes tan acostumbradas a los esplendores del talento y fue otra vez saboreada con deleite y otra vez aplaudida con entusiasmo. Después dejó escuchar su elocuente palabra el diputado a Cortes de esta capital, Sr. Muro, pronunciando un discurso magnífico, dedicado todo a elogiar el pensamiento de la instalación del Ateneo y a alentar a la juventud vallisoletana para seguir por ese camino tan glorioso [...]

Acto continuo, tomó la palabra el secretario de la Diputación Provincial, Sr. Callejo; y después de decir algunas muy sentidas y elocuentes sobre el objeto que allí reunía a todos, improvisó unos preciosos versos, que gustaron tanto más, cuanto que salían de la boca de una persona respetable por sus años y por su sabiduría.

La concurrencia recorrió, por último, los diversas estancias de la casa y se retiró luego sumamente complacida y entusiasmada [...]

Para terminar, en nombre de D. Eduardo de Ozcáriz, de Don Emilio Ferrari y D. Albino Madrazo, y en el mío, como iniciadores que somos del pensamiento, doy las gracias a todos los que nos han ayudado a la realización de nuestro proyecto y con especialidad a la prensa local, sintiendo que La Crónica Mercantil haya permanecido más indiferente de lo que debiera y menos complaciente y exacta de lo que hubiéramos deseado. Cabiéndole la gloria al Museo de haber sido el iniciador de tal idea cumpliendo de esta manera uno de los fines que nos propusimos los redactores al encargarnos de él. 
ANSElmo SALVÁ, «Discurso pronunciado por D.- en la apertura del Ateneo literario de la casa de Cervantes, el día 2 de junio de 1872», El Norte de Castilla (Valladolid), año XVIII, nos. 4660-4661, martes 11-VI-1872 (hojs. 1r, cols. 3-5, y 1v, cols. 1-2) y miércoles 12-VI-1872 (hojs. 1r, cols. $3-4 ; 1 v$, cols. $1-5$, y $2 r$, cols. 1-2).

Señores: La sociedad que hoy tiene la satisfacción de inaugurar sus tareas, ha encomendado al que os dirige la palabra, que es el más humilde de sus individuos, la difícil misión de redactar y leer el discurso acostumbrado en actos de esta naturaleza.

No cuento con las necesarias dotes para llevarla a cabo felizmente; pero tengo, en cambio, la esperanza de que, al contemplar mi pequeñez, reconoceréis también mi buen deseo, otorgándome vuestra indulgencia, sin la cual mi situación en este momento sería en extremo penosa.

Todos sabéis el objeto que aquí nos reúne. Valladolid ha tenido algún tiempo la ingratitud de mantener en el olvido la memoria del ilustre escritor español Miguel de Cervantes Saavedra, a pesar de que un monumento glorioso que hay en su seno, mansión en otro tiempo de este peregrino ingenio, se ofrecía constantemente a su vista; pero el espíritu civilizador del siglo, la cultura progresiva de la población en que habitamos y el amor ardiente que muchos castellanos profesan a las bellas letras españolas, tenían que promover una sublevación contra la apatía en que ha estado sumido este pueblo, excitando los ánimos y disponiéndolos para levantar una gloria patria de la postración en que nunca debió yacer.

Así ha sucedido en efecto; jóvenes entusiastas e infatigables concibieron la preciosa idea de crear un centro, donde a la par que se honrara la memoria del inmortal Cervantes, se estimulase a los amantes de la literatura, para cultivarla asiduamente; pronto vieron acogido su proyecto con entera complacencia por la juventud más distinguida y por personas de indisputable mérito; y arraigando en sus ánimos el propósito de realizar a toda costa sus laudables planes, hicieron suya la humilde casa en que habitó el genio a quien pretendían rendir homenaje, reclutaron en poco tiempo un número considerable de cervantistas decididos, adquirieron el apoyo inestimable de la prensa y comenzaron, en fin, no sin trabajos y sinsabores, a organizar el Ateneo que regocija en estos momentos a los ilustrados castellanos.

Yo desearía que el público que tiene la bondad de escucharme, hubiese presenciado las juntas preparatorias celebradas con este motivo; en ellas se han manifestado un entusiasmo honroso, una decisión inquebrantable y una fuerza de voluntad poderosa. Bien sabe Dios que consigno esto con sumo placer; ya porque puede servir de satisfacción a los fundadores de esta sociedad, ya también porque conviene que sepáis, que se han vencido dificultades imponentes, no siendo la menor el retraimiento general ocasionado por las circunstancias políticas del país.

Por fortuna ningún obstáculo ha sido poderoso hasta el punto de impedir la realización de tan noble proyecto; con el pensamiento fijo en el fin propuesto y sin temor a los esfuerzos más duros, se establecieron las 
bases de la sociedad, se nombró una comisión organizadora para practicar todo lo necesario al objeto, que ha trabajado heroicamente en el cumplimiento de su cometido, y visto el buen éxito de las gestiones, se señaló este día para celebrar solemnemente la apertura, eligiendo una junta directiva provisional, de la que soy el miembro más indigno.

Aquí tenéis, sucintamente narrada, la pequeña historia del Ateneo literario que se ha erigido en honor de Cervantes. Ahora que conocéis sus fines y que estáis indudablemente dispuestos a protegerle con vuestro eficaz apoyo, seguid prestándome vuestra benévola atención; pues quiero deciros algo del insigne autor del Quijote, como tema de mi sencillo y pobre discurso. Conozco que mis frases os serán poco gratas, porque carecen de valor y belleza; y no se me oculta tampoco, que lamentáis que yo sea el encargado de dirigiros la palabra; porque ¡cuántos de mis queridos compañeros no hubieran podido recrear vuestra inteligencia con sus notables pensamientos, sus profundos conceptos y su bello lenguaje! Aceptad, empero, mis palabras y si su rudeza os demuestra la escasez de mi inteligencia, la alegría que debe reflejarse en mi semblante, os revelará el entusiasmo de que estoy poseído en estos momentos.

De Cervantes dije que os hablaría y casi estoy arrepentido. Todos conocéis mejor que yo su biografía; todos habéis leído sus obras de literatura; todos admiráis sus proezas de soldado. ¿Qué puedo, por lo tanto, decir, que sea nuevo para vosotros? Es verdad que al evocar el recuerdo de tan grande hombre mil ideas se agolpan en la imaginación; pero ninguna se adapta al asunto que las inspira, el cual basta por sí solo para anonadar el entendimiento más elevado.

Cervantes a quien muchos admiran inconscientemente, arrastrados por esa irresistible atracción que acompaña a su nombre, debiera renacer de tiempo en tiempo para consumar de nuevo la prodigiosa obra que llevó a cabo por medio de su inmortal Quijote; en muchas ocasiones se ha sentido la necesidad apremiante de un genio, bastante poderoso para imponer al mundo sus justos deseos y sus razonables opiniones, cortando las funestas tendencias que con frecuencia se notan en el cultivo de las letras y destruyendo teorías y doctrinas incompatibles con el buen gusto que debe presidir a las concepciones del ingenio humano.

Se han manifestado de cuando en cuando en las obras posteriores al ilustre manco de Lepanto, cualidades y condiciones, halagüeñas al parecer, pero en realidad perniciosas; y sin un oportuno correctivo, sin una inteligencia bastante ilustrada para juzgarlas y bastante atrevida para rechazarlas, han ido poco a poco formando parte constitutiva del carácter general de la literatura, con harto menoscabo de la belleza y no menos perjuicio del público.

La afición desmedida a ciertas lecturas extravagantes que dominaba en los tiempos del desgraciado cautivo de Argel, que por cierto ejercía una terrible influencia en las costumbres y aspiraciones de aquellas gentes, recibió la muerte de un hombre que no dudó en oponerse abiertamente al gusto de su época, para modificarle a su antojo y desviar a sus contemporáneos de un camino que conducía a un abismo seguro.

He aquí que hoy necesitamos quien haga una cosa parecida. Otra extravagancia de peor índole se ha introducido en las aficiones de nuestra 
sociedad, respecto a las letras, y se está fomentando con las infinitas lecturas que existen poco a propósito para robustecer el entendimiento y educar el corazón.

La literatura de nuestro país se encuentra actualmente como es notorio, en un decaimiento deplorable, por más que del presente siglo se haga una calificación muy alta. Los adelantos materiales que hoy sirven nuestras necesidades y nuestros antojos, son ya una muestra sorprendente y maravillosa del inmenso poder que sabe conquistarse el hombre; pero nuestra época ofrece un contraste poco grato, entre estos inapreciables productos de la civilización que invade las naciones y el carácter, las ideas y las costumbres de los pueblos.

Apenas se evoca el recuerdo de pasados tiempos, cuando en nuestra imaginación se dibujan cuadros halagüeños en que se ven los actos practicados por aquellas generaciones; en medio de ella la lira del poeta sonaba incesantemente, sembrando en las inteligencias el germen de útiles conocimientos y despertando en los corazones los más delicados afectos y el deseo de las más generosas empresas. Quizá por esta razón se encontraban entonces con sorprendente frecuencia esos actos heroicos que tan claramente dicen el origen divino del alma humana, esas figuras llenas de grandeza que embellecen extraordinariamente la historia y esos sentimientos que han sido el móvil de asombrosos hechos: he aquí todo lo que ha servido para inmortalizar en la memoria de las generaciones posteriores, aquella época caballeresca que distingue la nación española de todas las del mundo y en la cual florecieron vates, cuyas producciones, son todavía, a pesar del tiempo transcurrido, el deleite más apetecido de las personas ilustradas.

El estilo de la poesía antigua y lo mismo el de la prosa servía perfectamente para expresar aquellas sublimes ideas, aquellos hermosos pensamientos, aquellos dulces afectos, que no han encontrado cabida en las imaginaciones de los siglos posteriores.

Actualmente el sentimiento de lo bueno y de lo bello existe acaso encerrado en muchos corazones; pero ninguno se atreve a manifestarle, temerosos todos de que el materialismo grosero de la época impida que sea acogido con el entusiasmo que merece. En cambio se inspiran casi todas las obras en el deseo insensato de agradar al público, para que éste las premie con su dinero y con sus aplausos; y con tan mezquina mira, no es posible reprender las costumbres, educar la inteligencia y deleitar el alma, que es y debe ser siempre la misión del escritor.

Éste pretende locamente imponer sus propias ideas a todo un pueblo, como si en realidad pudieran servir de norma al pensamiento humano; quiere probar por medio de sus vicios, que no hay virtudes, por medio de sus errores que no hay verdades, por medio de sus desengaños que no hay fe, y por medio de sus malos hábitos que no hay bondad.

$\mathrm{Y}$ de este modo han venido perdiéndose creencias e ideas que en los tiempos anteriores formaban el encanto de las almas elevadas; y las opiniones continúan extraviándose, y las costumbres se corrompen, y las inteligencias sin fuentes de inspiración dignas de su poder, se degradan, y el escepticismo cunde, apoderándose de todos los corazones y siendo la principal mancha de la literatura moderna. 
Ancho campo se abría a los autores españoles para combatirle y ese deber tenían; porque entre las clases vulgares que son en las que más acceso encuentran y más pronto filtran esas ideas negativas, casi siempre revestidas de apariencias de razón, se conservan ciertas preocupaciones, hasta cierto punto naturales, sobre las obras que produce cualquier ingenio, a las que conceden una autoridad infalible.

Pero las tendencias y propósitos levantados no siempre obtienen el triunfo: hoy los autores temen la impopularidad, la adversa fortuna, la oscuridad; y conociendo que la mayoría de las gentes en esta época de disolución atiende las necesidades de la materia con preferencia a las del espíritu, sirven aquéllas, y olvidan éstas, para que alentando las generales inclinaciones y evitando el oponerse a ellas con consejos que merecerían cruda guerra, puedan lograr los halagos de la fama y de la suerte.

Algo contribuye a este fatal resultado la falta de protección que los gobiernos han mantenido siempre para los cultivadores de las bellas letras; pues si estos no viesen su existencia pendiente de todo el mundo y adquiriesen la independencia de que disfruta en España el último y más inepto industrial, ya se aventurarían desde luego a arrostrar con valor las iras del público exhibiéndole continuamente la fealdad de sus hábitos, presentándole los atractivos del idealismo que tiene un altar escondido en casi todas las almas, y dedicándose siempre a propagar la bondad, puesto que la bondad es la esencia de la belleza y la belleza el primer objeto de la literatura.

Una especie de código literario, compuesto por una inteligencia superior, capaz de elevarse sobre todas con una autoridad incontrastable, e inspirado en los nobles sentimientos de abnegación y generosidad, haría seguramente todo esto, declararía una guerra tenaz a esos instintos sucios que despiertan muchas obras de actualidad, ya del género de la novela, ya del dramático, desdeñaría las aspiraciones de la materia para privarlas de alimento y consumirlas de este modo, excitaría siempre y con una constancia pasmosa los nobles deseos del alma, que por su origen divino está naturalmente inclinada al bien y a la grandeza y enseñaría que las obras del ingenio humano deben siempre producir algo.

Porque todo aquello que piensa el hombre para comunicarlo a los demás, no debe ser estéril; debe al contrario, contener algún beneficio positivo, no para el cuerpo, porque entonces llegaría a dominar al espíritu, sino para el alma, que halla un dulce y apacible recreo en todo lo que alienta sus elevadísimas tendencias; y las obras de que no se desprende enseñanza moral alguna, no pueden complacerla, porque queda como es lógico, desencantada enteramente, cuando en su lectura no ha encontrado nada que la demuestre el valor de sus nobles sentimientos, estimulándola para conservarlos con los puros goces que interesándoles por medio del libro, pueden proporcionarla.

Ahora noto, señores, que me he apartado de Cervantes, objeto principal que debió ser de mi discurso, por entrar en estas ligeras consideraciones sobre el carácter de nuestra literatura; aunque por otra parte, ya dejé consignado que sobre aquel inmortal genio nada se me ocurría que no estuviese de antemano en el pensamiento de todos los que me escuchan, 
por lo cual me creo dispensado de ocupar vuestra atención con vulgaridades que seguramente os desagradarían.

Cervantes patrocinando con su augusto nombre la sociedad que hoy para bien de este pueblo inauguramos, será sin duda objeto de una veneración profunda en lo sucesivo y recordará constantemente a todos los amantes de las bellas letras, que en sus obras está la lengua castellana como único modelo de que deben servirse los que pretendan usarla, para expresar sus pensamientos.

El Ateneo literario procurará mantener siempre creciente el culto que desde hoy empezamos a rendir de una manera pública al Príncipe de los ingenios españoles, y espera que de sus trabajos literarios hechos con noble intención y voluntad firmísima ha de resultar algún provecho para la Capital de Castilla la Vieja.

Cruel sería, en verdad, recibir un desengaño; porque vendría a probar que esa vergonzosa indiferencia con que hemos mirado generalmente unos asuntos que tanto interesan a la sociedad y que tan saludable influjo ejercen en la educación moral de los pueblos, proseguía aún para nuestra mengua; pero rechacemos la más mínima sospecha sobre este punto. La capital que ha logrado adquirir una importancia colosal en todos los ramos, que cuenta por hijos suyos, renombrados poetas, insignes publicistas y oradores notables, que tiene una Universidad de la que salen frecuentemente talentos admirables y en la que cultiva siempre la ciencia una juventud brillante y de grandes esperanzas, que sostiene en la prensa numerosos órganos de la opinión popular, principales representantes de la literatura y que guarda en su seno hombres distinguidos en la ciencia, en la política y en las artes, no puede consentir que decaiga en lo más mínimo una sociedad destinada exclusivamente a dar honor y gloria continuos, a Miguel de Cervantes, al Príncipe de los ingenios, al regocijo de las musas, al orgullo de España, al primer talento de nuestra nación, que tantos ha producido.

También desea la sociedad que hoy abre al público sus puertas, que todas las clases sociales se aprovechen de los beneficios que pueda reportar.

Penétrese el proletariado de la necesidad que tiene de ilustrarse, para que no se deje fácilmente alucinar por doctrinas falaces que le exponen a las más tristes contingencias y acuda con resolución a escuchar algo que acaso nunca habrá oído; pues el mayor deseo de esta sociedad, es ser útil al que más necesita las luces de la instrucción.

Sepa también el hombre sabio, que su cooperación en el Ateneo puede producir algunos buenos servicios para las letras y algún provecho para los que quieran servirse de la sociedad como medio instructivo, y no vacile en otorgarla, dando así mayor autoridad y más fuerza a las importantes cuestiones que se ventilen.

El político, el orador, el poeta, el artista, todos hacen falta para consolidar esta obra, cuyo cimiento estamos poniendo, y que, si se cumplen mis deseos y los de todos cuantos me escuchan, llegará a ser un monumento de eterna gloria, que elevará a una altura fabulosa el buen nombre de este ilustrado pueblo.

Para concluir, señores, permitidme que, en nombre de la sociedad signifique mi agradecimiento a las distinguidísimas personas que han tenido 
la bondad de solemnizar el acto con su presencia, probando una vez más, su profunda ilustración y lo dispuestas que están a apoyar toda asociación digna de una capital culta.

También quiero dar infinitas gracias a la prensa de la localidad, que con un ardor propio de sus vastos conocimientos en la carrera literaria, ha propagado la idea que hoy realizamos, cediendo, además, sus columnas generosamente, para la publicación, si era necesaria, de todos los documentos concernientes al asunto.

No me sorprende esta conducta de mis dignos compañeros; pues siempre les he visto al lado de todos los pensamientos nobles y grandes, sin atender su procedencia y sin escatimar ningún género de sacrificios en favor de las buenas causas. De hoy en adelante, los periodistas vallisoletanos, contarán con un lauro más, por haber contribuido tan considerablemente a enaltecer el nombre de Cervantes y a poner a Valladolid y su provincia al nivel de las más adelantadas poblaciones.

Gracias en fin, a todos cuantos se hallan aquí reunidos y con especialidad a las amables señoras y a las simpáticas señoritas que han venido para amenizar con su bondad las unas, con su hermosura las otras esta solemne fiesta, y cuyo rasgo de generosidad no olvidaremos nunca los que tan dichosos nos consideramos hoy en su presencia.

Quiera Dios conceder larga vida y frutos copiosos a este Ateneo que con tan nobles propósitos comienza en este día sus tareas. No dejará de prosperar por poca diligencia en los socios, ni por falta de entusiasmo en los que le apoyan, ni por el desdén del público. Sólo circunstancias muy raras y muy extraordinarias podrán atajarle en su carrera; y tales circunstancias, confiemos en que nunca se presentarán y en que si se presentaren, sabrá vencerlas el noble empeño de todos cuantos tenemos la obligación de conservar el honor del nombre castellano.

He dicho.

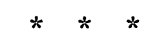

FERMÍN HERRÁN, "Inauguración de un Ateneo literario en Valladolid en la casa que vivió Cervantes», Crónica de los Cervantistas (Cádiz), año I, núm. 5, 10-VIII-1872, pp. 164-166.

Discurríamos un día por las calles de Valladolid, tres trasnochadísimos escritores, amantes de nuestras glorias literarias y entusiastas admiradores del inmortal Miguel de Cervantes; y acaeció venturosamente que fuimos a terminar el curso de nuestra peregrinación a la antigua casa que habitó el gran Ingenio en la calle del Rastro, número 14. Indagamos quién era el dueño; nos dirigimos a él aquella misma tarde, y, amable y más entusiasta de lo que a primera vista parecía, nos invitó a que la visitásemos, lo cual hicimos con poca resistencia por nuestra parte, a pesar de la incomodidad que le causábamos y con gran contentamiento de nuestro espíritu, naturalmente algo exaltado en semejantes momentos, por los recuerdos que dicha morada traía a nuestra memoria. Hallábase aquélla 
desalquilada y pensamos en adquirirla; proyecto que inmediatamente pusimos en conocimiento de su dueño.

Al día siguiente publicaban los periódicos de la localidad una carta firmada por Eduardo de Ozcáriz, Emilio Ferrari, Albino Madrazo y el que estas líneas escribe, manifestando la conveniencia de establecer en la casa referida una sociedad o Academia, y convocando con tal objeto a todos los amantes del inmortal autor del Quijote a una reunión para llevar a feliz remate nuestros propósitos.

Este es el origen del Ateneo literario La Casa de Cervantes, que está llamado a ejercer grande influencia en pro de la ilustración de esta capital.

"Gacetillas», El Norte de Castilla (Valladolid), año XVIII, núm. 4797, viernes 22-XI-1872, hoj. 2r, col. 2.

Otra junta. Esta noche a las ocho se reunirá la Sociedad cervantista, en una de las salas de la Casa Consistorial, para resolver algunos asuntos de vital importancia a la misma.

«Gacetillas», El Norte de Castilla (Valladolid), año XVIII, núm. 4799, domingo 24-XI-1872, hoj. 2r, col. 3.

Reunión. Anteanoche no pudo celebrarse el certamen anunciado por el Ateneo Cervantista, por falta de asistencia de socios, acordándose su traslado para el martes próximo en sesión pública.

Daremos más pormenores oportunamente, lamentando la apatía que se observa en asuntos tan importantes para la literatura. Excitamos a la juventud estudiosa de esta capital a que procure el fomento y vida de este Ateneo.

«Gacetillas», El Norte de Castilla (Valladolid), año XVIII, núm. 4800, martes 26-XI-1872, hoj. 2r, col. 2.

Certamen público. El Ateneo literario bajo el nombre de «La Casa de Cervantes» celebra esta noche a las siete sesión pública en el salón bajo de las Casas Consistoriales. Está encargado del discurso el distinguido joven y apreciable amigo nuestro D. Emilio Pérez Ferrari, y además de los señores que gusten hacer uso de la palabra, tenemos entendido hablarán $\mathrm{D}$. José Muro, D. Gregorio Barragán y D. Juan Callejo, leyéndose composiciones poéticas de los Sres. Estrañi y Arroyo (D. Martín).

No dudamos que la sesión estará en extremo animada, conocidas como son del público las especiales dotes que concurren en las personas encar- 
gadas de dar al primer certamen la importancia literaria que creemos ha de obtener.

Por nuestra parte, felicitamos a la Sociedad literaria, excitándola a que siga con la misma actividad que hasta aquí y procurando vencer cuantos obstáculos pudieran presentársela. Tiempo era ya de que Valladolid contase con un centro de discusión como el indicado y del que tan ventajosos resultados puede prometerse la juventud estudiosa.

«Gacetillas», El Norte de Castilla (Valladolid), año XVIII, núm. 4805, domingo 1-XII-1872, hoj. 2r, col. 2.

Ya avisaremos. Por efecto de las circunstancias, tampoco se verificó en la noche del viernes el certamen literario anunciado, en obsequio del inmortal Cervantes, autor del idioma castellano. Indicaremos a nuestros lectores el día en que la junta del expresado Ateneo determine su celebración.

Eleuterio Díez Rodríguez, "Discurso leído el 25 de diciembre de 1875 por el Sr. D.-, referente a la casa que habitó Cervantes en Valladolid por los años de 1603 a 1605, núm. 14 de la calle del Rastro, en la sesión inaugural del salón de reuniones en dicha casa", en La casa de Cervantes en Valladolid. Sociedad Literaria, Científica y Artística. Composiciones leídas en la sesión inaugural de 25 de diciembre de 1875 y en la de 23 de abril de 1876, aniversario 260 de la muerte de Cervantes. Valladolid, Imp. y Lib. Nacional y Extranjera de Hijos de Rodríguez, 1876, pp. 5-6.

[...] Entusiastas los actuales poseedores como el que más, de las glorias de Cervantes, deseábamos tener la casa todo lo mejor posible a causa de ser visitada con alguna frecuencia, hasta que en 1872 se creó en ella un Ateneo compuesto de treinta socios, jóvenes en su mayoría y todos ellos amantes de la bella literatura, jlástima fue que no pudiera sostenerse por falta de recursos materiales, pues en el corto tiempo de existencia se presentaron trabajos muy dignos, de los cuales conservamos algunos! [...]

«El centenario del Quijote. Una carta de Ferrari», El Imparcial, 10-XII-1903, p. 1.

Allá por los años del 72 -ya ha llovido... cervantismo desde entonceshabía en Valladolid un grupo de mozalbetes entusiastas y fervorosos por todo cuanto era digno de entusiasmo y fervor; un tanto alborotados y 
discutidores, curiosos de todo y empeñados siempre en inocentes empresas. Como el «cenáculo» bullía y zumbaba a modo de una colmena, tenía cierta fuerza de atracción para los pasajeros y gentes volanderas, que, por lo que hace a muchas hormigas indígenas, molestadas en sus útiles tareas por el ruido de aquellas cigarras, agotaban para los dichos rapaces el vocabulario del desprecio, tachándoles de ilusos y chiflados, de coplerillos ociosos que ¡oh delito! sacaban cosas de su cabeza.

Pues señor, ello fue que puesta ya por el Municipio la lápida conmemorativa en la casucha miserable que debía convertirse en templo, como dice el Cervantes de Serra, aconteció que un extranjero, de paso en la ciudad fue a dar, como otros tantos, no con las corporaciones oficiales ni con los personajes conspicuos, pero con el inevitable grupillo de adolescentes indocumentados. Mostró en seguida ansia de visitar la que fue vivienda del autor de Don Quijote, y uno de los cinco o seis muchachos, creo que el mismo que dirige a usted estas líneas, con la imprevisora audacia de los pocos años, se brindó a acompañarle, encontrándose ambos a poco ante aquel edificio humilde, cuya puerta estaba cerrada a piedra y lodo. Después de aporrearla largo rato, comprendiendo la extrañeza del viajero, asomóse al balcón una mujer desarrapada y sucia.

- ¿Qué deseaban ustedes?

-Queríamos ver la casa de Cervantes.

— «Aquí no vive ese señor».

Y diciendo así la inquilina del venerando templo cerró el balcón refunfuñando.

Mi acompañado era un inglés - que por lo general los protagonistas de estas anécdotas son ingleses-, pero no por esto se dude de la exacta verdad de este relato. Mi hombre se quedó tan escandalizado, como corrido el «cicerone», quien hubiera querido que se le tragase la tierra con lo que iría a dar en el Esgueva, digno sepulcro, según sus lecturas de Góngora y Quevedo en aquella vergonzosa situación.

Referido el lance a los compañeros, se acordó inmediatamente arrendar la casa a fin de conservarla y tenerla abierta al público, celebrando además en ella reuniones dedicadas a honrar la memoria de la mayor gloria europea. Así nació con el nombre de "La Casa de Cervantes» una modesta tertulia [...]. 